
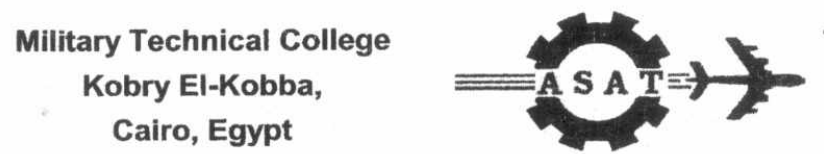

11-th International Conference on Aerospace Sciences \&

Aviation Technology

\title{
DESIGN OPTIMIZATION AND GEOMETRIC ANALYSIS \\ OF THE SLOTTED SOLID PROPELLANT GRAINS
}

\author{
Zayed, A-N. *
}

\section{ABSTRACT}

Three different categories, of the slotted solid propellant grains, are optimized from the point of view of the configuration parameters. The optimization process, of the main dimensions and the length ratio, is built on the conditions of filling coefficient and clamping factor. The grain geometry is analyzed to calculate the burning perimeters through the web thickness as a tool to predict the burning performance during the burning time. The effect of the length ratio on the performance of the burning perimeter is investigated to obtain the optimal length ratio for each configuration.

KEYWORDS: Rocket motor, Solid propellant, Internal burning, Slotted grains.

\section{NOMENCLATURES}

$A_{b}$ : burning surface area

$A_{c . c h}$ : cross-sectional area of combus-tion chamber

$A_{f}$ : free area (port area)

$A_{p}$ : propellant cross-sectional area

b : web thickness of grain

e : burnt distance

$\overline{\mathrm{e}} \quad$ : dimensionless parameter $=\mathrm{e} / \mathrm{b}$

$I_{s}:$ specific impulse

$\mathrm{K}_{\mathrm{C}}$ : clamping factor

$\mathrm{K}_{\mathrm{FC}}$ : filling coefficient

L : grain length

$L_{1} \quad$ : length of slotted portion

$L_{2}$ : length of tubular portion

$\dot{m}$ : mass flow rate

$\mathrm{n}$ : number of slots $\mathrm{r}$ : burning rate

$\mathrm{R}$ : outer grain radius

$\mathrm{R}_{1}$ : inner grain radius

$\mathrm{S}$ : burning perimeter

$\overline{\mathrm{S}}$ : dimensionless parameter $=\mathrm{S} / \mathrm{R}$

$\mathrm{x}$ : x-coordinate

y : y-coordinate

$\beta \quad$ : grain angle of symmetry

$\delta \quad$ : slot width

$\varphi$ : slot angle

$\lambda$ : length ratio $=L_{1} / L$

$\rho:$ radius ration $=R_{1} / R$, density

$\psi:$ slot width ratio $=\delta / \mathrm{R}$

* Egyptian Armed Forces 


\section{INTRODUCTION}

Slotted grains consist of two portions, the first is slotted of length " $L_{1}$ " where the burning is on the core and slots surfaces, the second is tubular of length " $L_{2}$ " where the burning is on the core surface only[1,2].

The slotted grain may be classified into three categories. The first category is the familiar slotted grains with three or four slots[1,3]. The second is the short-slot grains of two, three, or four short slots $[2,4,5]$. The third category is the slotted grains for dual thrust [2] which are composed of two parts of different propellants as boosting and sustaining phases of burning. The burning of the third category is in the three dimensions.

For each of those categories, the design optimization is made to obtain the optimal dimensions which fulfill the recommended filling coefficient $[2,4]$ and the condition of equality of the mass flow rate per unit free area $[4,6]$. Because of the complexity of merging of these two conditions, the optimization process has been implemented through an iterative method of equality.

The obtained thrust, of a solid propellant rocket motor, is directly proportional to the burning perimeter of the grain cross-section $[4,5,8]$. Therefore, the effect of the variation of the configuration parameters $(\lambda$ and $\varphi)$ on the performance of the burning perimeter during the burning time is studied and analyzed.

A verification, of predicting the thrust-time curve from the calculated variation of the burning perimeter during the burning time, has been presented for a real solid propellant rocket motor containing a slotted grain

\section{SLOTTED GRAINS}

Figure 1 presents a three dimensional configuration of a 3-slot and 4-slot grains with the lengths of the first and second portions.

\section{Design Optimization}

The optimization process, of the slotted grain geometry, is made for fulfilling the following two conditions:

- The grain dimensions fulfils the recommended filling coefficient $[2,4]$ which has the value of 0.85 , where the filling coefficient is defined as

$$
K_{F C}=\frac{A_{p}}{A_{c . c h}}
$$

- The equality of the mass flow rate " $\dot{m}$ " per unit free area " $A_{f}$ " of the slotted portion and the tubular portion $[1,4,5,6]$. In other words, the equality of the clamping factor " $\mathrm{K}_{\mathrm{C}}$ " of the two portions, where the clamping factor is defined as $[1,3,7]$

$$
K_{c}=\frac{A_{b}}{A_{f}}
$$


Figure 3, Table 1, and Table 2 present the dimensionless parameters $\rho$ and $\psi$ for different values of $\lambda$. These results shows that an increasing of $\lambda$ leads to an increasing of $\delta$ and a decreasing of $R_{1}$. In the case of a 3-slot grain, the limits of $\lambda$ are 0.325 and 0.52 because $\lambda<0.325$ leads to very narrow $\delta$ and $\lambda>0.52$ leads to $\delta>$ $R_{1}$. In the case of a 4-slot grain, the limits of $\lambda$ are 0.3 and 0.5 because $\delta$ is very narrow when $\lambda<0.3$ and $\delta \approx \mathrm{R}_{1}$ at $\lambda>0.5$.

Table 1 The dimensionless parameters $\rho$ and $\psi-v s-\lambda$ for 3-slot grains

\begin{tabular}{|l|l|l|l|l|l|l|l|l|l|}
\hline$\lambda$ & 0.325 & 0.350 & 0.375 & 0.400 & 0.425 & 0.450 & 0.475 & 0.500 & 0.520 \\
\hline$\rho$ & 0.332 & 0.301 & 0.273 & 0.248 & 0.225 & 0.205 & 0.186 & 0.169 & 0.156 \\
\hline$\psi$ & 0.063 & 0.089 & 0.109 & 0.123 & 0.134 & 0.142 & 0.149 & 0.153 & 0.156 \\
\hline
\end{tabular}

Table 2 The dimensionless parameters $\rho$ and $\psi-v s-\lambda$ for 4 -slot grains

\begin{tabular}{|c|c|c|c|c|c|c|c|c|c|}
\hline$\lambda$ & 0.300 & 0.325 & 0.350 & 0.375 & 0.400 & 0.425 & 0.450 & 0.475 & 0.500 \\
\hline$\rho$ & 0.305 & 0.272 & 0.243 & 0.218 & 0.196 & 0.176 & 0.159 & 0.143 & 0.129 \\
\hline $\boldsymbol{\psi}$ & 0.065 & 0.082 & 0.094 & 0.103 & 0.109 & 0.114 & 0.117 & 0.119 & 0.120 \\
\hline
\end{tabular}

\section{Geometric Analysis}

The purpose of this section is to calculate the burning perimeter through the web thickness (during the burning time). This calculations are made at each incremental burnt distance "e" which varies from zero to " $b$ ", that is to detect the different phases of burning.

\section{Three-slot grains}

There is no variation in the geometry of the 3-slot grains $\left(\alpha=30^{\circ}\right)$ but the dimensions vary due to the variation of $\lambda$ which leads to different values of $R_{1}$ and $\delta$ as shown in Fig. 3 and Table 1. The burning perimeters, of 3 -slot grains are presented in Fig. 4 for $\lambda=0.4$ and $\lambda=0.5$. In Fig. $4(\mathrm{a})$ where $\lambda=0.4$, the burning perimeter is of regular shape and consists of two segments $\left(S_{1}\right.$ and $\left.S_{2}\right)$ up to the end of burning, that is because the web thickness of the slot surface " $b_{\text {slot }}$ " is greater than that of the circular surface " $\mathrm{b}_{\text {circl". }}$ ".

$$
b_{\text {slot }}>b_{\text {circl }}
$$

This condition is satisfied when:

$$
\cos \alpha-\psi / 2>1-\rho
$$

In Fig. 4 (b) where $\lambda=0.5$, the circular segment " $\mathrm{S}_{2}$ " is vanished after a certain burnt distance and $b_{\text {slot }}<b_{\text {circl }}$ which means that the burning time of the slotted portion is 
As shown in Fig. 2, the filling coefficient may be formulated as

$$
\mathrm{K}_{\mathrm{FC}}=\frac{\pi \mathrm{R}^{2}-\pi \mathrm{R}_{1}^{2}-\mathrm{n} \delta\left(\mathrm{R}-\mathrm{R}_{1}\right)}{\pi \mathrm{R}^{2}}=0.85
$$

Let $R_{1}=\rho R$, then Eq. (2) is re-written as

$$
\begin{aligned}
& \pi \rho^{2} R^{2}+n \delta R(1-\rho)=0.15 \pi R^{2} \\
& \pi \rho^{2} R+n \delta(1-\rho)=0.15 \pi R
\end{aligned}
$$

The equality of the mass flow rate " $\dot{m}$ " per unit free area " $A_{f}$ ", of the two portions, is expressed as

$$
\begin{gathered}
\left(\frac{\dot{m}}{A_{f}}\right)_{1}=\left(\frac{\dot{m}}{A_{f}}\right)_{2} \longrightarrow\left(\frac{A_{b} \cdot \rho \cdot r}{A_{f}}\right)_{1}=\left(\frac{A_{b} \cdot \rho \cdot r}{A_{f}}\right)_{2} \\
\left(\frac{A_{b}}{A_{f}}\right)_{1}=\left(\frac{A_{b}}{A_{f}}\right)_{2} \longrightarrow\left(\frac{S \cdot L}{A_{f}}\right)_{1}=\left(\frac{S \cdot L}{A_{f}}\right)_{2}
\end{gathered}
$$

which means the equality of the clamping factor. Then, from Fig. 2,

$$
\frac{S_{1} \cdot L_{1}}{A_{f 1}}=\frac{S_{2} \cdot L_{2}}{A_{f 2}} \longrightarrow \frac{L_{1}[2 \pi \rho R-n \delta+2 n(R-\rho R)]}{\pi \rho^{2} R^{2}+n \delta(R-\rho R)}=\frac{2 \pi \rho R L_{2}}{\pi \rho^{2} R^{2}}
$$

Equation (6) can be re-arranged in the following form

$$
\delta=\left[\frac{2 \pi \rho^{2}\left(L_{1}-L_{2}\right)+2 n \rho L_{1}(1-\rho)}{2 n L_{2}(1-\rho)+n \rho L_{1}}\right] R=\psi R
$$

Let $L_{1}=\lambda L$ and $L_{2}=(1-\lambda) L$, then Eq. (7) is re-formed as

$$
\delta=\left[\frac{2 \pi \rho^{2}(2 \lambda-1)+2 n \rho \lambda(1-\rho)}{2 n(1-\lambda)(1-\rho)+n \rho \lambda}\right] R=\psi R
$$

By substitution of Eq. (8) in Eq. (4), one can get

$$
\pi \rho^{2}+n\left[\frac{2 \pi \rho^{2}(2 \lambda-1)+2 n \rho \lambda(1-\rho)}{2 n(1-\lambda)(1-\rho)+n \rho \lambda}\right](1-\rho)=0.15 \pi
$$

Because of the complexity of Eq. (9), this equation is solved for $\rho$ by implementing a software to make iteration on $\rho$ up to fulfil the equality of the two sides of the equation, that is at a certain value of $\lambda$. Then substitute the value of $\rho$ in Eq.(8) to get the value of $\psi$. By obtaining the values of $\rho$ and $\psi$, the optimal dimensions of the grain are determined. 
smaller than that of the tubular portion. To optimize this case, Eq.(10) has to be of equal sides, i.e.

$$
\cos \alpha-\psi / 2=1-\rho
$$

which can be fulfilled exactly at $\lambda=0.45$.

\section{Calculation of the burning perimeter}

As shown in Fig. 4(a) and for $\lambda \leq 0.45$, the burning is a single phase and its perimeter is calculated as

$$
\left.\begin{array}{rl}
\mathrm{S} & =\mathrm{S}_{\text {slot }}+\mathrm{S}_{\text {tub }} \\
& =6\left(\mathrm{~S}_{1}+\mathrm{S}_{2}\right)+2 \pi\left(\mathrm{R}_{1}+\mathrm{e}\right)
\end{array}\right\}
$$

where

$$
\begin{aligned}
& S_{1}=\sqrt{R^{2}-\left(\frac{\delta}{2}+e\right)^{2}}-\sqrt{\left(R_{1}+e\right)^{2}-\left(\frac{\delta}{2}+e\right)^{2}} \\
& S_{2}=\left(R_{1}+e\right)(\beta-\alpha) \\
& \beta=\tan ^{-1}\left(\frac{\sqrt{\left(R_{1}+e\right)^{2}-(\delta / 2+e)^{2}}}{\delta / 2+e}\right)
\end{aligned}
$$

In the case of $\lambda>0.45$, as shown in Fig. $4(\mathrm{~b})$, the burning has two phases. The perimeter of the first phase is calculated as in Eq.(12) and that of the second phase is calculated as in the following.

$$
S=6 S_{12}+2 \pi\left(R_{1}+e\right)
$$

where

$$
S_{12}=\sqrt{R^{2}-\left(\frac{\delta}{2}+e\right)^{2}}-\left(\frac{\delta}{2}+e\right) \cdot \tan \alpha
$$

Figure 5 illustrates the performance of the dimensionless burning perimeters " $\bar{S}$ " of the slotted and tubular portions separately through the burning time and at different values of $\lambda$, where

$$
\left.\begin{array}{l}
\bar{S}_{\text {slot }}=\frac{S_{\text {slot }} \cdot L_{1}}{R L}=\frac{S_{\text {slot }} \cdot \lambda}{R} \\
\bar{S}_{\text {tub }}=\frac{S_{\text {tub }} \cdot L_{2}}{R L}=\frac{S_{\text {tub }}(1-\lambda)}{R}
\end{array}\right\}
$$

Figure 6 shows the performance of the total perimeter of the grain at different values of $\lambda$. From these two figures, one can see that the optimal value of $\lambda$ for a 3 -slot grain is 0.45 where the performance of the burning perimeter is quasi-neutral in addition to the advantage that, at this value of $\lambda$, the web thickness of both portions are equal. 


\section{Four-slot grains}

In the case of a 4-slot grain, the feature of the burning perimeter depends on two parameters, the first is the slot angle " $\varphi$ " and the second is the length ratio " $\lambda$ ". As shown in Fig. 7, the grains of different slot angle have different shapes of the burning perimeters. Also as presented in Table 2, the grains of different length ratios have different dimensions $\left(R_{1}\right.$ and $\delta$ ) depending on the grain radius $R$.

\section{Calculation of burning perimeter}

As illustrated in Fig. 8, assume that the center of the grain is at the origin of the $x-y$ plane. By determining the coordinates of points $A, B, C$, and $D$; the length of the segments of the burning perimeters, at a certain burnt distance "e", can be calculated as follows:

$$
\left.\begin{array}{l}
x_{A}=\frac{-2 m k+\sqrt{(2 m k)^{2}-4\left(1+m^{2}\right)\left(k^{2}-R^{2}\right)}}{2\left(1+m^{2}\right)} \\
y_{A}=\sqrt{R^{2}-x_{A}^{2}} \\
x_{B}=\frac{-2 m k+\sqrt{(2 m k)^{2}-4\left(1+m^{2}\right)\left(k^{2}-\left(R_{1}+e\right)^{2}\right)}}{2\left(1+m^{2}\right)} \\
y_{B}=\sqrt{\left(R_{1}+e\right)^{2}-x_{B}^{2}}
\end{array}\right\}
$$

where $\quad m=\tan \varphi$ and $k=(\delta / 2+e) / \cos \varphi$

then, $\quad x_{C}=x_{A}+(2 e+\delta) \sin \varphi \quad y_{C}=y_{A}-(2 e+\delta) \cos \varphi$

$$
\begin{array}{ll}
\mathrm{x}_{\mathrm{D}}=\mathrm{x}_{\mathrm{B}}+(2 \mathrm{e}+\delta) \sin \varphi & \mathrm{y}_{\mathrm{D}}=\mathrm{y}_{\mathrm{B}}-(2 \mathrm{e}+\delta) \cos \varphi \\
\varphi_{1}=\frac{\pi}{2}-\tan ^{-1}\left(\frac{\mathrm{y}_{\mathrm{B}}}{\mathrm{x}_{\mathrm{B}}}\right) & \varphi_{2}=\tan ^{-1}\left(\frac{\mathrm{y}_{\mathrm{D}}}{\mathrm{x}_{\mathrm{D}}}\right)
\end{array}
$$

The burning perimeter, as shown in Fig. 8 , is calculated as

where

$$
\left.\begin{array}{rl}
\mathrm{S} & =\mathrm{S}_{\text {slot }}+\mathrm{S}_{\text {tub }} \\
& =4\left(\mathrm{~S}_{1}+\mathrm{S}_{2}+\mathrm{S}_{3}+\mathrm{S}_{4}\right)+2 \pi\left(\mathrm{R}_{1}+\mathrm{e}\right)
\end{array}\right\}
$$

$$
\begin{array}{ll}
S_{1}=\overline{A B}=\sqrt{\left(x_{A}-x_{B}\right)^{2}+\left(y_{A}-y_{B}\right)^{2}} & S_{2}=\left(R_{1}+e\right) \varphi_{1} \\
S_{3}=\overline{C D}=\sqrt{\left(x_{C}-x_{D}\right)^{2}+\left(y_{C}-y_{D}\right)^{2}} & S_{4}=\left(R_{1}+e\right) \varphi_{2}
\end{array}
$$

Figure 9 shows the performance of the dimensionless burning perimeters " $\bar{S}$ " of the slotted and tubular portions separately, as defined in Eq.(14), through the burning time and at different values of $\lambda$ and $\varphi$. This figure contains a matrix of curves, each row represents the perimeters of grains of the same length ration and each column represents the perimeters of grain of the same slot angle. From this figure, it is clear 
that the slot angles of $45^{\circ}$ and $50^{\circ}$ are rejected because the web thickness of the slotted portion is smaller than that of the tubular portion. The following forms state the equality of the web thickness.

$$
\begin{aligned}
\mathrm{R} \sin \varphi-\delta / 2 & \approx \mathrm{R}-\mathrm{R}_{1} \\
\sin \varphi-\psi / 2 & \approx 1-\rho
\end{aligned}
$$

Also, the length ratio of 0.5 is rejected for the same reason and the cases of $\lambda=0.45$ are only accepted for $\varphi \geq 65^{\circ}$. The cases which fulfill Eq.(22) are as follows:

$$
\begin{array}{llll}
\text { - grain of } & \varphi=55^{\circ} & \text { and } & \lambda=0.37 \\
\text { - grain of } & \varphi=60^{\circ} & \text { and } & \lambda=0.40 \\
\text { - grain of } & \varphi=65^{\circ} & \text { and } & \lambda=0.45
\end{array}
$$

Figure 10 shows the performance of the total perimeters of 4-slot grains of different length ratios and slot angles. The cases which give a quasi-neutral performance of the burning perimeter are the mentioned cases which fulfil Eq.(22).

\section{SHORT-SLOT GRAINS}

The short-slot grains may be found with 2, 3, or 4 short slots as shown in Fig. 11. The main dimensions of a short-slot grain, are $\mathrm{R}, \mathrm{R}_{1}$, and $\delta$ as presented in Fig. 12.

\section{Design Optimization}

For short-slot grains, the condition of the filling coefficient $=0.85$ can be formed as

$$
2 n\left[\frac{\pi}{4} \psi^{2}+\psi\left(2 \rho-\frac{1}{2} \sqrt{\rho^{2}-\psi^{2}}\right)+\frac{1}{2} \rho^{2} \varphi_{0}\right]=0.15 \pi
$$

where

$$
\varphi_{o}=\alpha-\beta \text { and } \beta=\frac{\pi}{2}-\frac{\pi}{n}
$$

The condition of equality of the clamping factors, of the slotted and tubular portions, is summarized to be in the following form.

$$
\frac{\lambda\left[\frac{\pi}{2} \psi+2 \rho-\sqrt{\rho^{2}-\psi^{2}}+\rho \varphi_{0}\right]}{\frac{\pi}{4} \psi^{2}+\psi\left(2 \rho-\frac{1}{2} \sqrt{\rho^{2}-\psi^{2}}\right)+\frac{1}{2} \rho^{2} \varphi_{o}}=\frac{2(1-\lambda)}{\rho}
$$

From Eq.(23) and (24), one can get 


$$
\frac{2 \mathrm{n} \lambda\left[\frac{\pi}{2} \psi+2 \rho-\sqrt{\rho^{2}-\psi^{2}}+\rho \varphi_{0}\right]}{0.15 \pi}=\frac{2(1-\lambda)}{\rho}
$$

Equation (25) is iterated for $\rho$ and $\psi$ at a certain value of $\lambda$. This iteration gives the optimal values of $\rho$ and $\psi$ at different $\lambda$ s as presented in Table 3 and shown in Fig. 13 . Note that $\delta$ here is half the slot width.

Table 3 Optimal values of $\rho$ and $\psi$-vs- $\lambda$ for short-slot grains

\begin{tabular}{|c|c|c|c|c|c|c|}
\hline \multirow{2}{*}{$\lambda$} & \multicolumn{2}{|c|}{ 2 short slots } & \multicolumn{2}{c|}{3 short slots } & \multicolumn{2}{c|}{ 4 short slots } \\
\cline { 2 - 8 } & $\rho$ & $\psi$ & $\rho$ & $\psi$ & $\rho$ & $\psi$ \\
\hline 0.350 & --- & -- & -- & -- & 0.3438 & 0.0332 \\
\hline 0.375 & -- & --- & 0.3519 & 0.0356 & 0.3219 & 0.0494 \\
\hline 0.400 & 0.3665 & 0.0304 & 0.3300 & 0.0568 & 0.3026 & 0.0644 \\
\hline 0.425 & 0.3432 & 0.0624 & 0.3090 & 0.0758 & 0.2835 & 0.0780 \\
\hline 0.450 & 0.3220 & 0.0905 & 0.2896 & 0.0931 & 0.2669 & 0.0910 \\
\hline 0.475 & 0.3011 & 0.1150 & 0.2711 & 0.1088 & 0.2497 & 0.1026 \\
\hline 0.500 & 0.2827 & 0.1373 & 0.2551 & 0.1239 & 0.2341 & 0.1137 \\
\hline
\end{tabular}

From Table 3 and Fig. 13, it is clear that the limits of $\lambda$ are as follows:

$$
\begin{array}{lll}
\text {-- for } 2 \text { short slots } & \lambda_{\min }=0.400 & \lambda_{\max }=0.50 \\
\text {-- for } 3 \text { short slots } & \lambda_{\min }=0.375 & \lambda_{\max }=0.50 \\
\text {-- for } 4 \text { short slots } & \lambda_{\min }=0.350 & \lambda_{\max }=0.50
\end{array}
$$

\section{Geometric Analysis}

The burning perimeters of the short slot grains (slotted portion) are divided into three segments of lengths $S_{1}, S_{2}$ and $S_{3}$ as shown in Fig. 14. Let the grain center is at the origin of the $x-y$ plane. Then, at a certain burnt distance "e", the segments are calculated as

$$
\begin{aligned}
& S_{1}=\left(R_{1}+e\right)\left(\varphi_{1}-\beta\right) \\
& S_{2}=2 R_{1}-y_{A}
\end{aligned}
$$

Where $\quad \beta$ is the grain angle of symmetry and $\varphi_{1}=\tan ^{-1}\left(\frac{y_{A}}{x_{A}}\right)$

$$
\begin{aligned}
x_{A}=\delta+e ; \quad & y_{A}=\sqrt{\left(R_{1}+e\right)^{2}-x_{A}^{2}} \\
- \text { If } e \leq\left(R-2 R_{1}-\delta\right) \longrightarrow & S_{3}=(\delta+e) \cdot \pi / 2 \\
\text { otherwise } & S_{3}=(\delta+e) \cdot \varphi_{2}
\end{aligned}
$$




$$
\begin{aligned}
& \text { where } \quad \begin{aligned}
\varphi_{2} & =\tan ^{-1}\left(\frac{y_{c}-2 R_{1}}{x_{C}}\right) \\
y_{c} & =\frac{R^{2}+4 R_{1}^{2}-(\delta+e)^{2}}{4 R_{1}} ; \quad x_{C}=\sqrt{R^{2}-y_{c}^{2}}
\end{aligned}
\end{aligned}
$$

The dimensionless burning perimeters are calculated as in Eq.(14) where

$$
\mathrm{S}_{\text {slot }}=2 \mathrm{n}\left(\mathrm{S}_{1}+\mathrm{S}_{2}+\mathrm{S}_{3}\right) \quad \mathrm{S}_{\mathrm{tub}}=2 \pi\left(\mathrm{R}_{1}+\mathrm{e}\right)
$$

Figure 15 illustrates the dimensionless burning perimeter -vs- the dimensionless burnt distance for short-slot grains at different length ratios " $\lambda$ ". All of the short-slot grains have a progressive first phase of burning, but the second phase is completely dependent on the length ratio. From the point of view of neutrality, $\lambda$ of 0.5 is the most suitable for grains with two short slots, and $\lambda$ of 0.4 is the most suitable for grains with three and four short slots.

\section{SLOTTED GRAINS FOR DUAL THRUST}

As shown in Fig. 16, this grain is composed of two parts. The first, which contains the slotted portion, is working as a booster and the second is working as a sustainer. The two parts are of different propellants[2]. The propellant of the booster is stronger (of higher burning rate, specific mass, and specific impulse) than that of the sustainer. The burning of the two parts are in series where the sustainer starts in burning at the burn-out of the booster.

\section{Design Optimization}

The same procedures of design optimization of slotted grains [Eq.(4) to Eq.(9)] are repeated with a little modification according to increasing the burning surface, of the slotted portion, by the amount of the slots ends. This addition leads to very little variation (in the fourth decimal) of the optimal values. Then the optimal values of $\rho$ and $\psi$, presented in Table 2, will be used in this section.

\section{The Web Thickness}

The web thickness of the boosting phase is determined according to the main dimensions of the slotted portion as shown in Fig. 17. It can be calculated as

$$
b_{b}=R \cdot \cos \varphi-\delta / 2
$$

According to the design requirement, the duration of the boosting phase can be controlled by changing the slot angle, the length ratio, and the burning rate of the booster propellant. Consequently, the web thickness of the sustaining phase is determined as 


$$
b_{s}=R-R_{1}-b_{b}
$$

The duration of the sustaining phase depends mainly on the burning rate of the sustainer propellant.

\section{Geometric Analysis}

The slotted portion of the booster burns in three directions. The circular surface of the core and the slot sides burn in two directions as shown in Fig. 7. At ends of the slots, the burning is in the third direction with the same web thickness of the boosting phase. Therefore, the burning surface area is calculated instead of the burning perimeter. Then, the burning surface of the booster " $\mathrm{A}_{b b}$ " is calculated from Fig. 8 and Fig. 18 as in the following.

$$
\begin{aligned}
A_{b b}=4\left[\left(S_{2}\right.\right. & \left.+S_{4}\right) L_{1}+\left(S_{1}+S_{3}\right)\left(L_{1}-b_{b}\right)+S_{5} \cdot S_{1} \\
& \left.+\delta\left(R-R_{1}-e\right)+S_{6} \cdot S_{2}\right]+2 \pi\left(R_{1}+e\right) L_{2}
\end{aligned}
$$

where $\mathrm{S}_{1}, \mathrm{~S}_{2}, \mathrm{~S}_{3}$, and $\mathrm{S}_{4}$ are the same as used in Eq.(20)

$$
\mathrm{S}_{5}=\mathrm{S}_{6}=\mathrm{e} . \pi / 2
$$

The burning surface of the sustainer is calculated (for $e>b_{b}$ ) as

$$
A_{b s}=\left(S_{3}+S_{4}\right) L_{1}+2 \pi\left(R_{1}+e\right) L_{2}
$$

The dimensionless burning surfaces area are defined as follows:

$$
\bar{A}_{b b}=\frac{A_{b b}}{R L} ; \quad \bar{A}_{b s}=\frac{A_{b s}}{R L}
$$

To predict the burning performance of this charge, of two different propellants, the burning surface of the sustainer is multiplied by a factor $\mathrm{K}$ which expresses the ratio between the specifications of the two different propellants.

$$
K=\frac{\mu_{s}}{\mu_{b}} \times \frac{r_{s}}{r_{b}} \times \frac{I_{s s}}{I_{s b}}
$$

where $\quad \mu_{\mathrm{b}}, \mu_{\mathrm{s}}$ : specific masses of the booster and sustainer propellants

$r_{b}, r_{s}$ : burning rates of the booster and sustainer propellants

$I_{b}, I_{S}$ : specific impulses of the booster and sustainer propellants

The effect of changing the slot angle on the burning performance is studied at a certain length ratio of 0.4 as presented in Fig. 19, where the factor $\mathrm{K}$ is taken 0.5 . From that figure, it is clear that increasing the slot angle leads to decreasing the web thickness of the booster with a little decreasing of the burning surface during the boosting phase and a little increasing of the burning surface during the sustaining phase which is slightly progressive. Note that increasing the slot angle is limited according to the length ration as presented in Table 4. 
Table 4 The maximum slot angle at different length ratios

\begin{tabular}{|c|c|c|c|c|c|c|}
\hline$x$ & 0.35 & 0.40 & 0.425 & 0.45 & 0.475 & 0.50 \\
\hline$q_{m}$ & 78.8 & 73.8 & 71.2 & 68.5 & 65.5 & 62.3 \\
\hline
\end{tabular}

Also, the effect of changing the length ration is studied at a certain slot angle of $62^{\circ}$ as shown in Fig. 20, where the factor $\mathrm{K}$ is taken 0.5 . This study shows that the lower length ratio gives a progressive boosting phase with a bigger web thickness and a higher burning surface during the sustaining phase. In the opposite case, the higher length ratio gives shorter and regressive boosting phase with longer and lower sustaining phase. In the case of a slot angle of $62^{\circ}$ and length ratio of 0.4 , the boosting and sustaining phases are quasi-neutral.

According to design requirements, the choices of the length ratio, slot angle, and the factor $\mathrm{K}$ determine the feature of the burning performance of the dual thrust slotted grains as a solid propellant charge.

\section{CONCLUSIONS}

For all slotted grains, the optimal main dimensions of the grain are completely dependent on the length ratio.

\section{For Slotted Grains:}

- In the case of 3-slot grains, the optimal length ratio is 0.45 .

- In the case of 4-slot grains, the optimal length ratio depends on the slot angle which is preferable to be greater than or equal $55^{\circ}$.

\section{For Short-Slot Grains:}

- The burning has two phases: the first phase is progressive while the second phase depends on the number of the short slots and the length ration of the slotted portion.

- In the case of 4-short-slot grains, the second phase is irregular.

\section{For Slotted Grain of Dual Thrust:}

- The burning has two phases: the first phase is slightly progressive for the minimum length ratio and slightly regressive for the maximum length ratio, while the second phase is slightly progressive for all cases.

- Decreasing the length ratio, of the slotted portion, leads to increasing the web thickness (consequently the burning time) of the first phase.

- Decreasing the slot angle leads to increasing the web thickness (consequently the burning time) of the first phase. 


\section{REFERENCES}

[1] Smolik, J and Ludvik, F., "Theory and Design of Rockets," MTC, Part II-a, Cairo, 1967.

[2] Smolik, J and Ludvik, F., "Theory and Design of Rockets," MTC, Part II-b, Cairo, 1967.

[3] Barrere, M., “Rocket Propulsion," Elsivier Publishing Company, 1960.

[4] "Solid Rocket Motor Performance Analysis and Prediction", NASA SP-8039, May 1971.

[5] Sutton, G. P., "Rocket Propulsion Elements," $4^{\text {th }}$ Edition, John Wiley \& Sons, Inc., ISBN 0-471-83836-5, 1976.

[6] Sutton, G. P., "Rocket Propulsion Elements," $6^{\text {th }}$ Edition, John Wiley \& Sons, Inc., ISBN 0-471-52938-9, 1992.

[7] Summerfield, M and Kuo, K.K., "Fundamental of Solid Propellant Combustion," AIAA Publication, Vol. 90, ISBN 0-915928-84-1, 1984.

[8] Zayed, A-N., "Geometric Analysis of Internal Burning Solid Propellant Grains", Proceeding of the 10-th AMME International Conference, MTC, Cairo, May 2002. 
(a) 3-slot Grain

(b) 4-slot grain

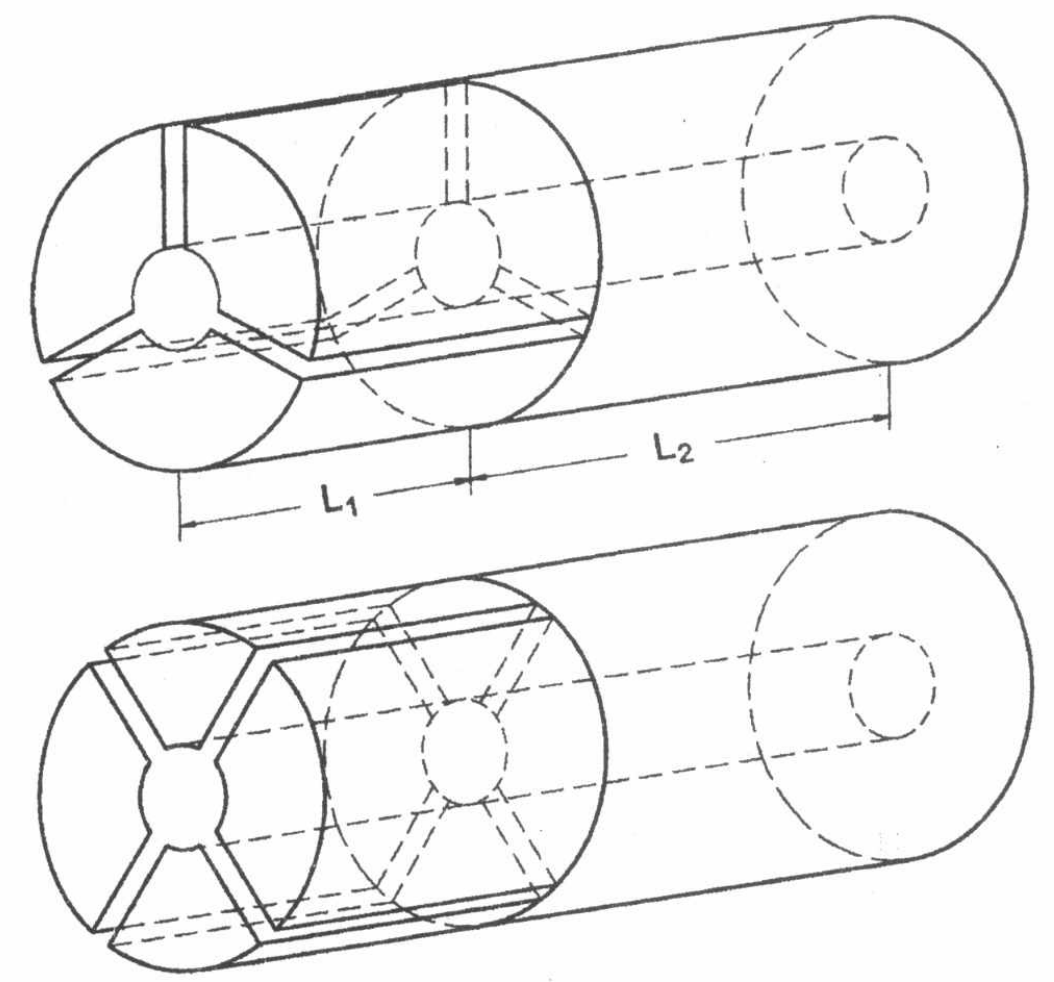

Fig. 1 Configuration of the slotted grains
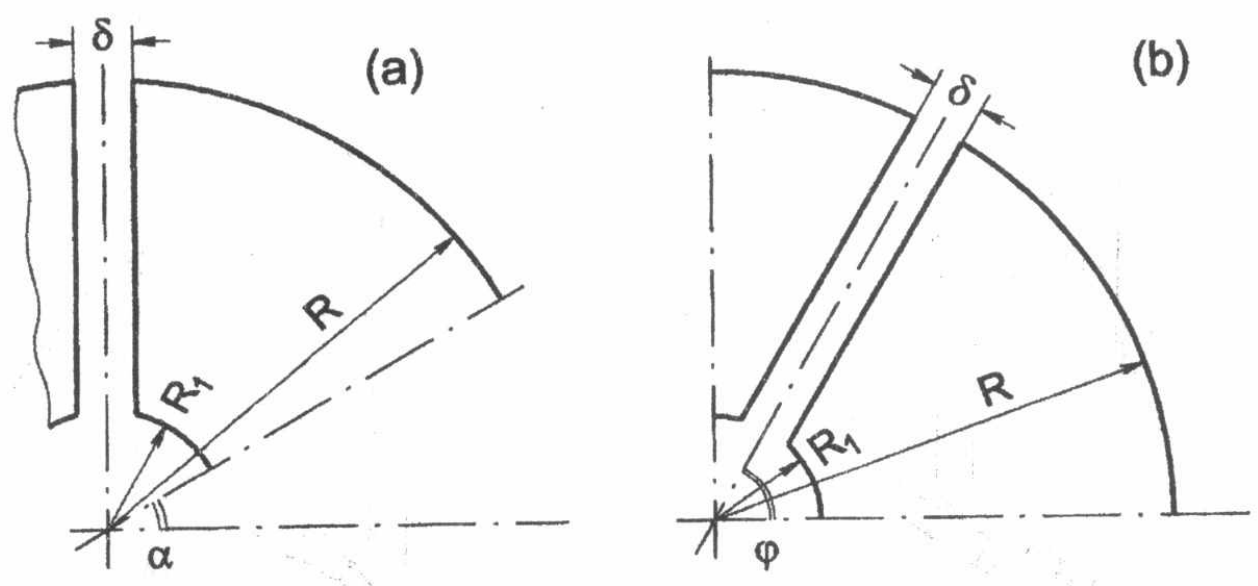

Fig.2 The main dimensions of the slotted grains 


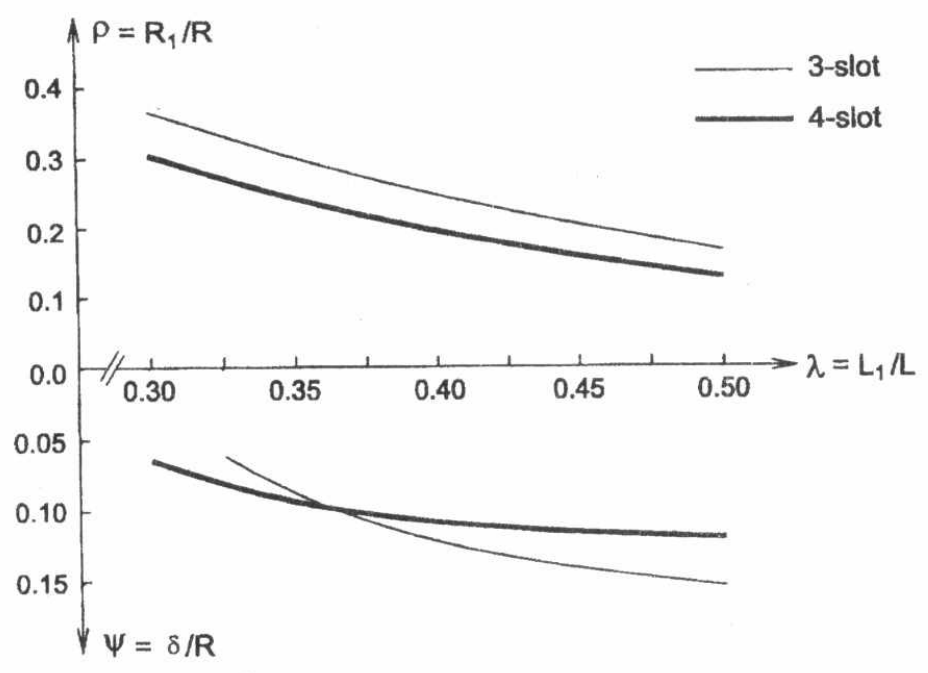

Fig. 3 The optimal values of $\rho$ and $\psi$ as function in $\lambda$
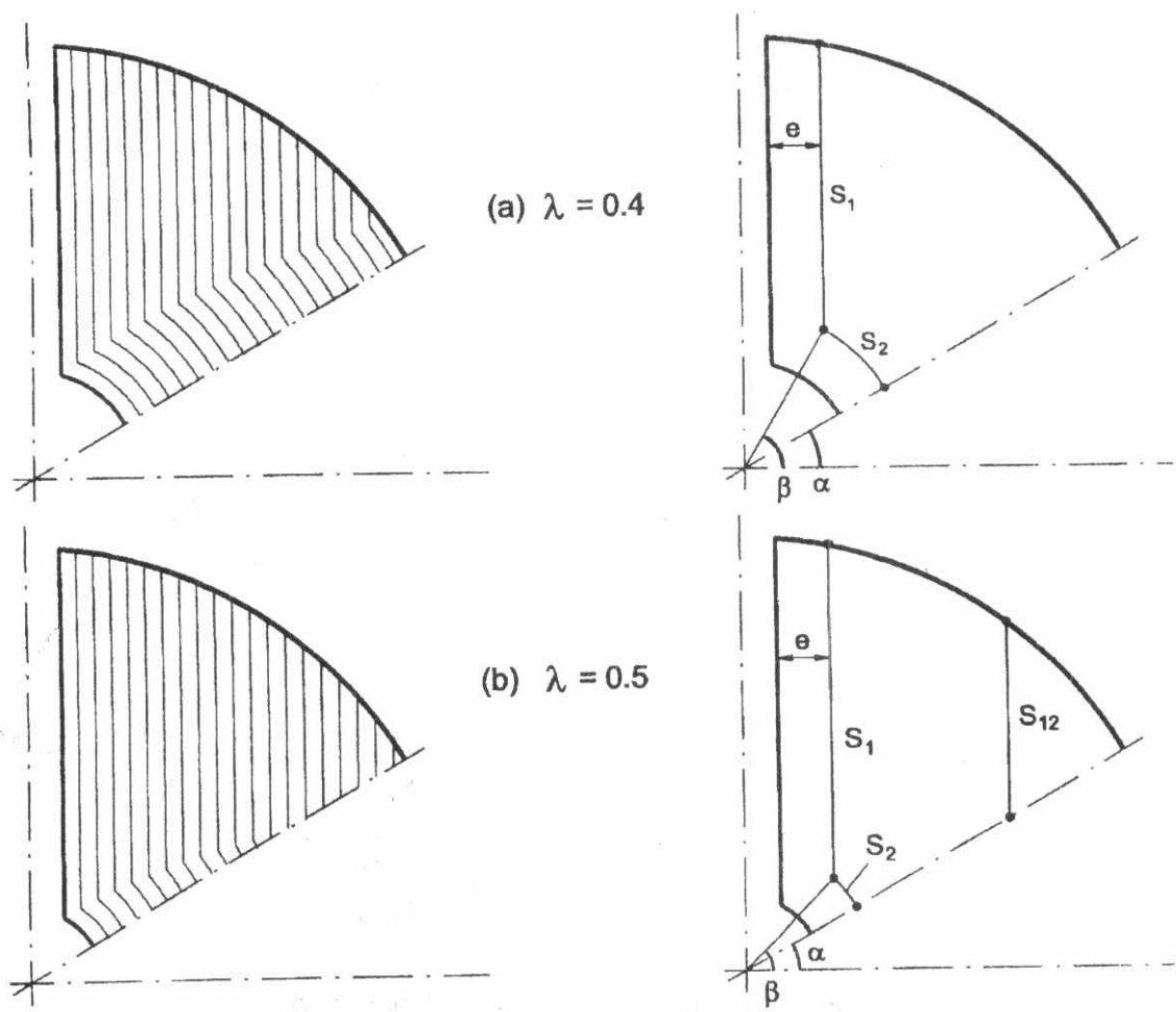

Fig. 4 The burning perimeters of 3-slot grains 

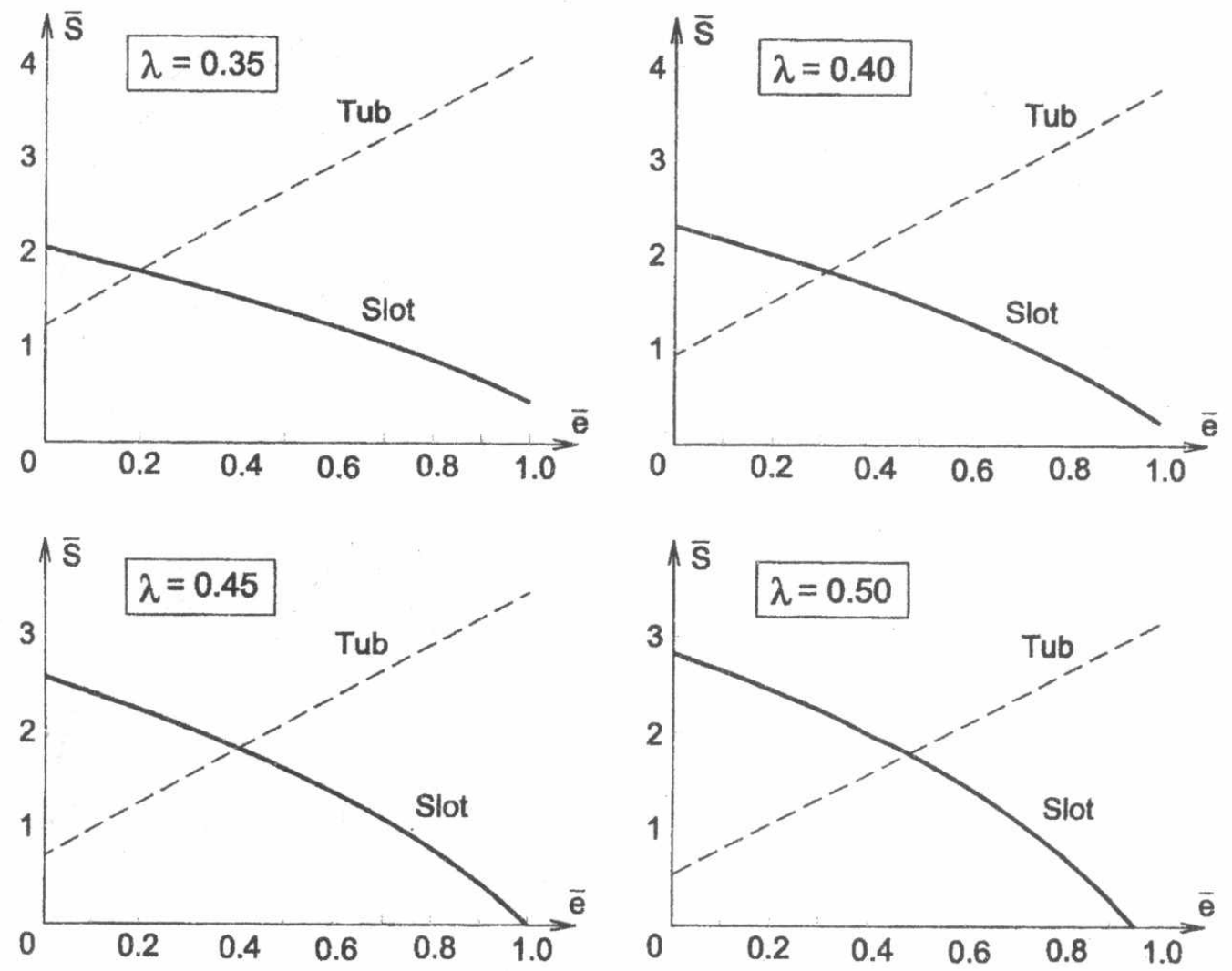

Fig. 5 The perimeters of each portion of 3-slot grains

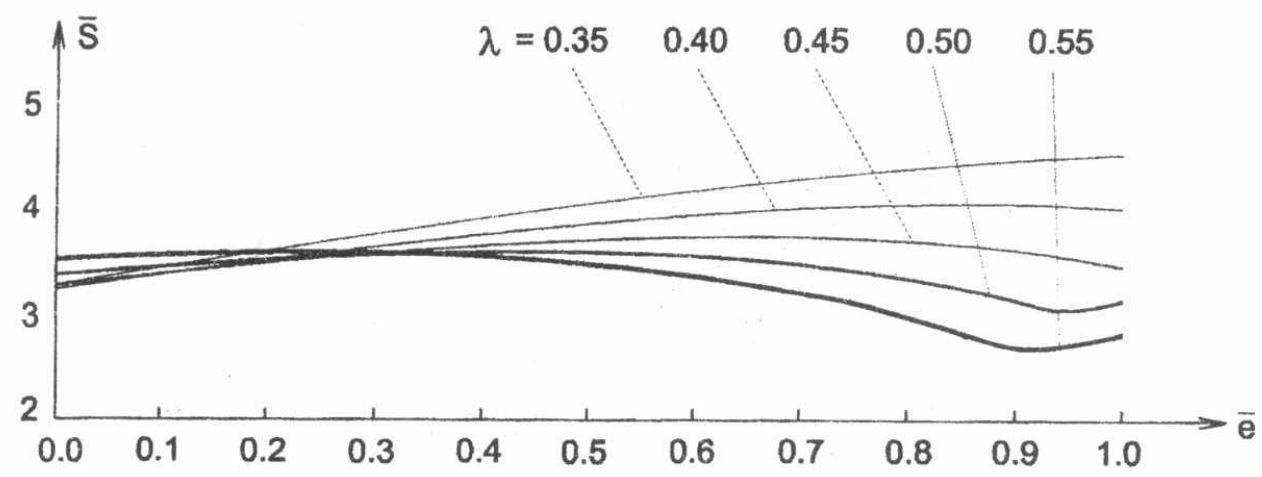

Fig. 6 The total perimeters of 3-slot grains of different length ratio 

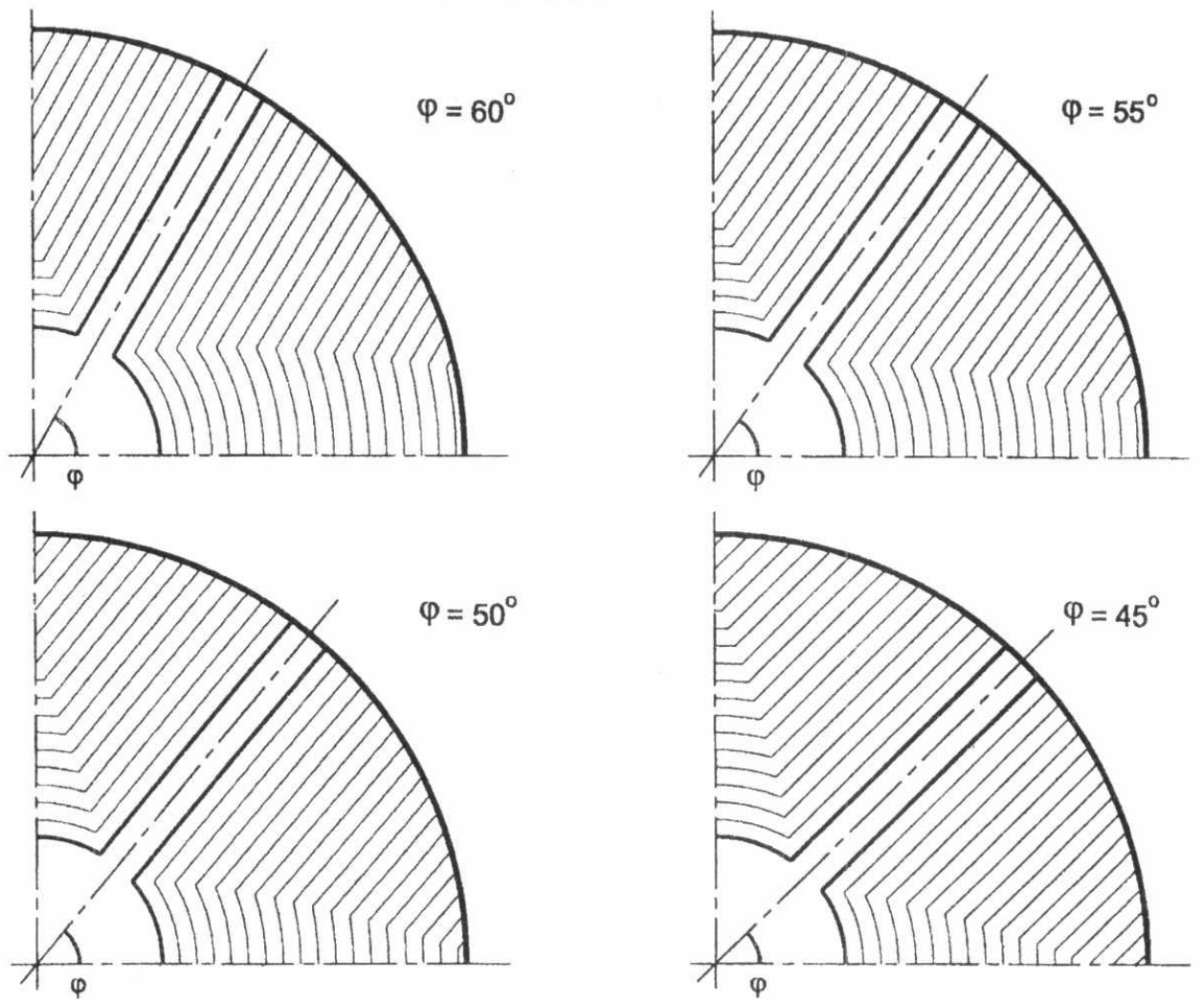

Fig.7 The burning perimeters of 4-slot grains of different slot angles

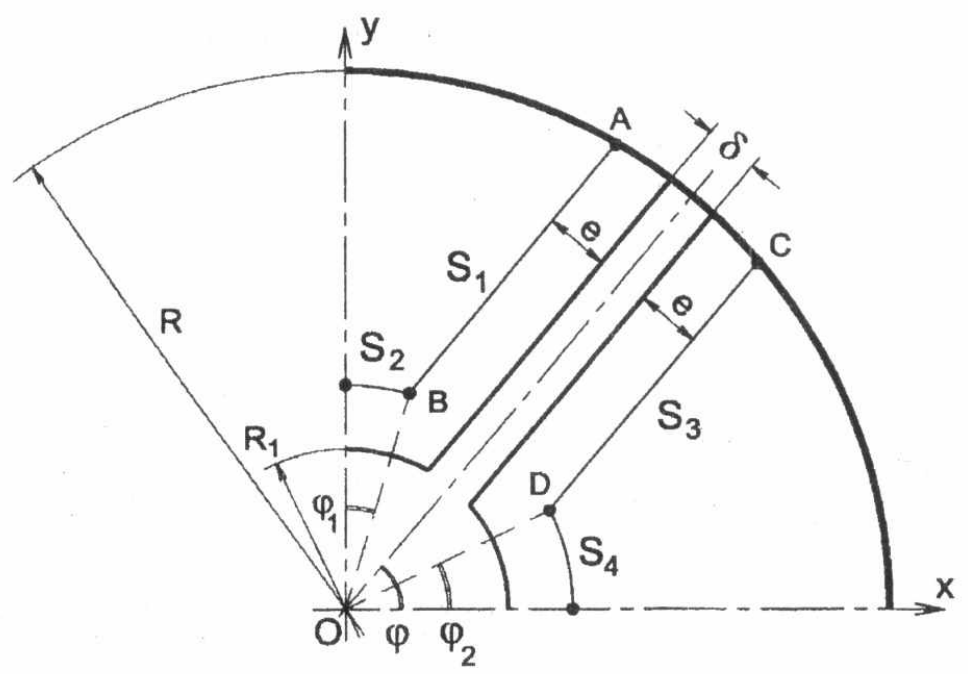

Fig. 8 Segments of the burning perimeter of a 4-slot grain 


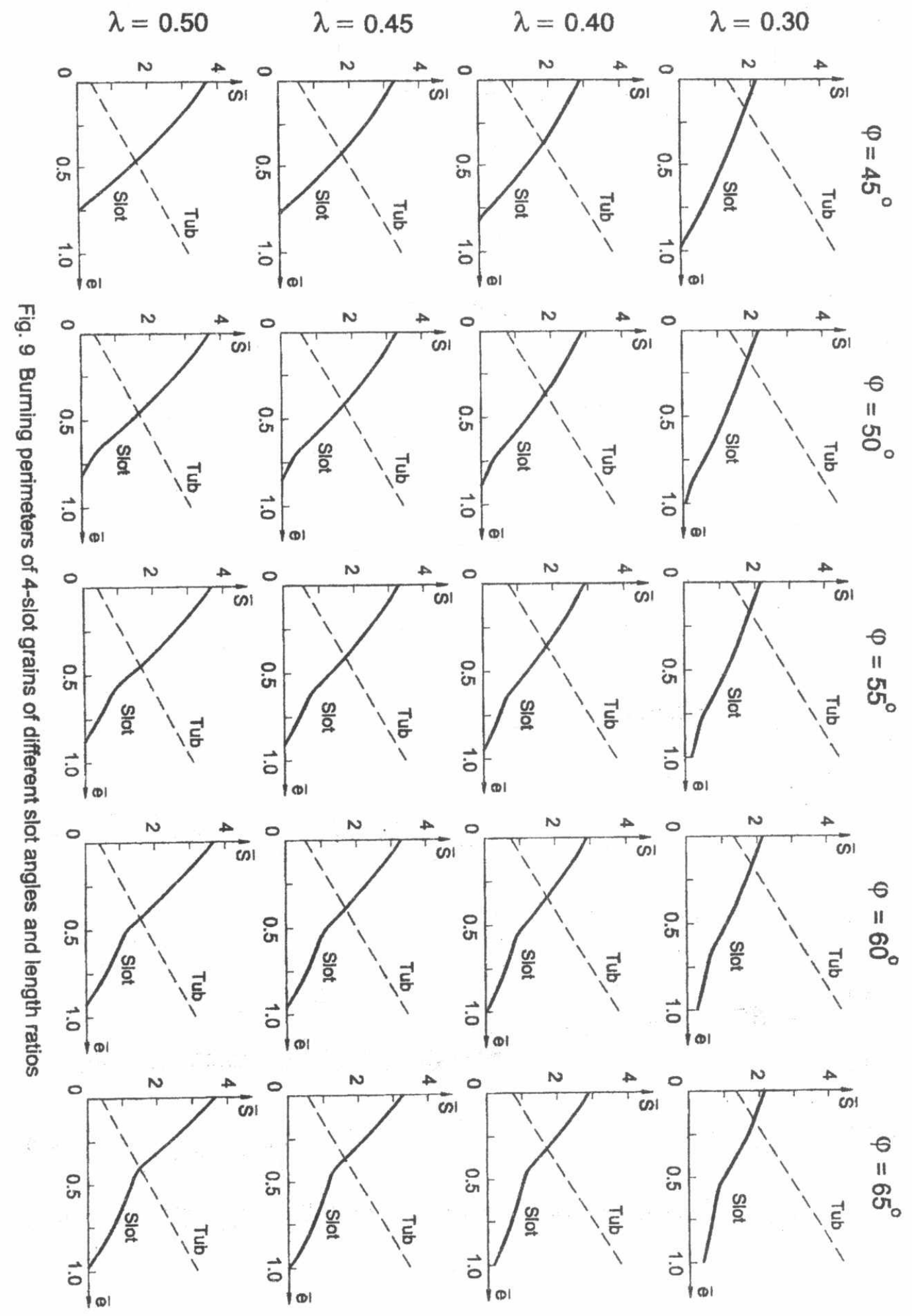



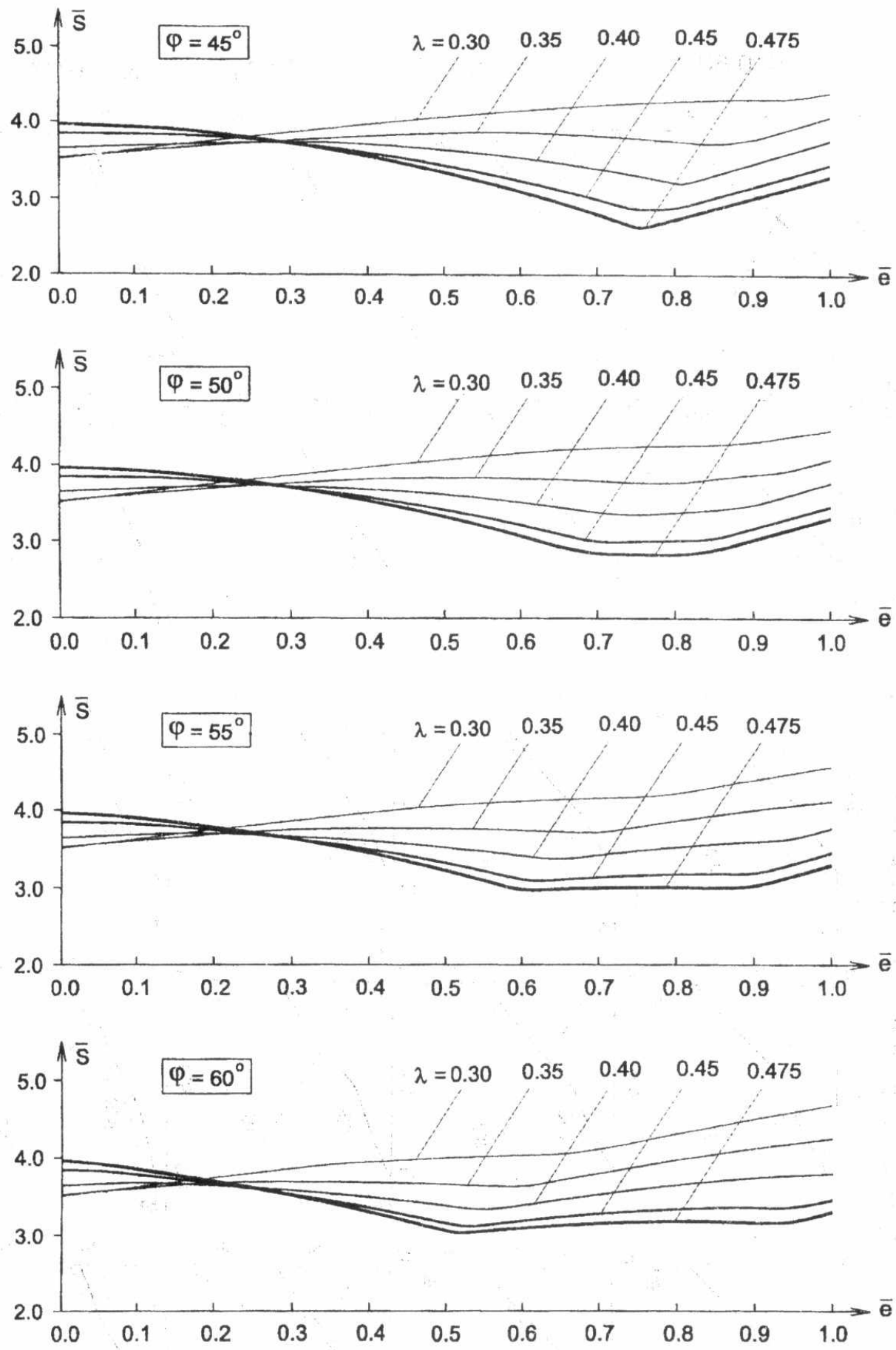

Fig. 10 The total perimeters of 4-slot grains of different slot angles and length ratio 


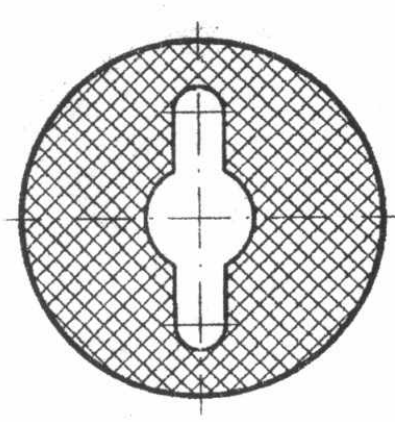

2 Short slots

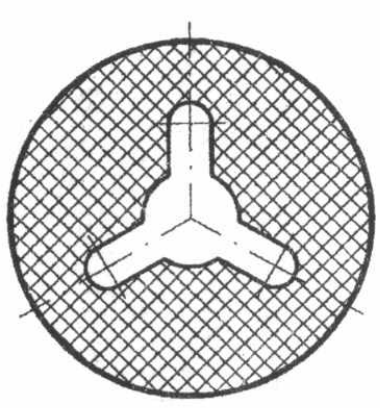

3 Short slots

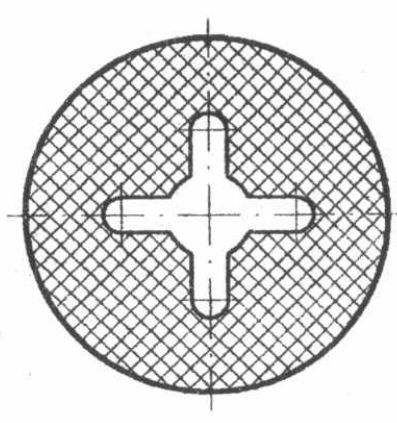

4 Short slots

Fig. 11 Configuration of short-slot grains

Fig. 12 The main dimensions of a short-slot grain

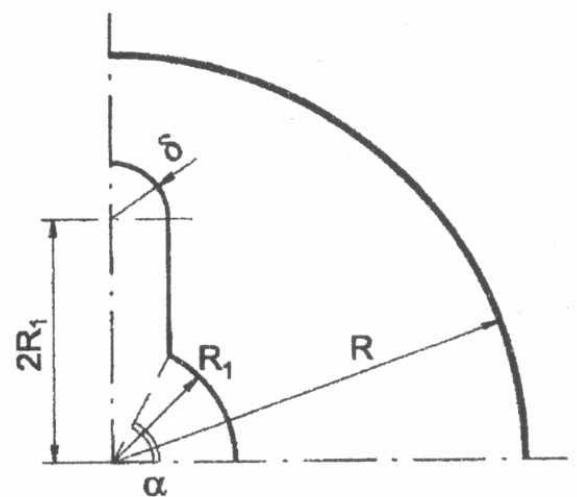

$\alpha$

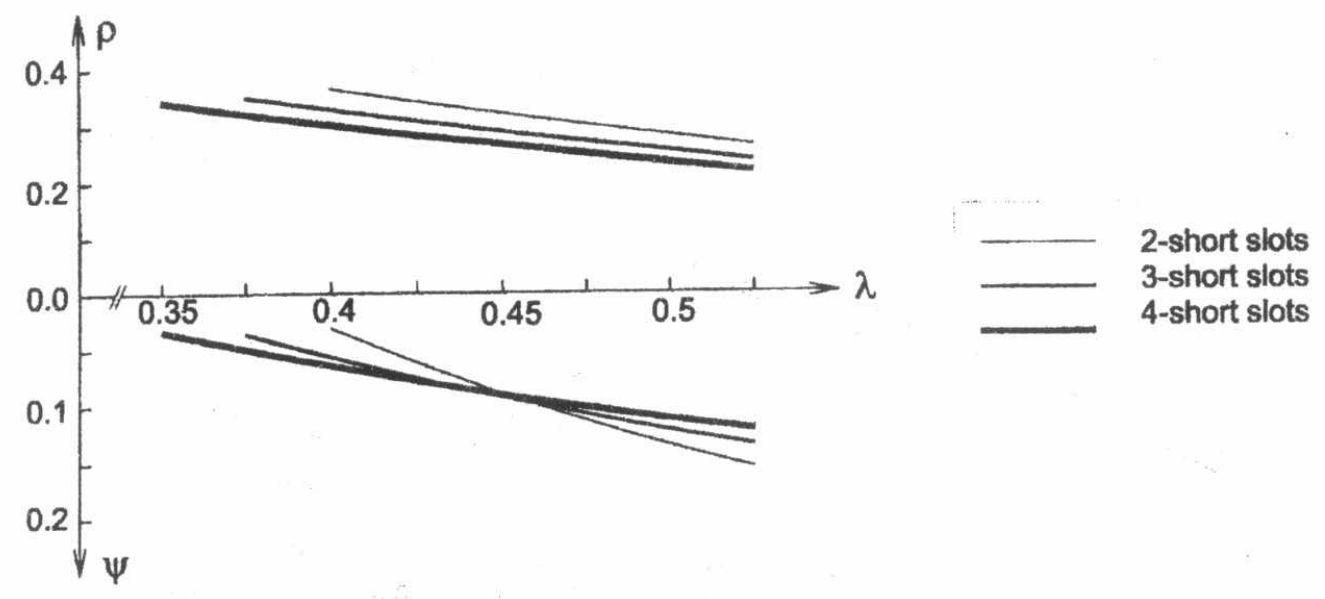

Fig. 13 The variation of $\rho$ and $\psi-v s-\lambda$ for short-slot grains 

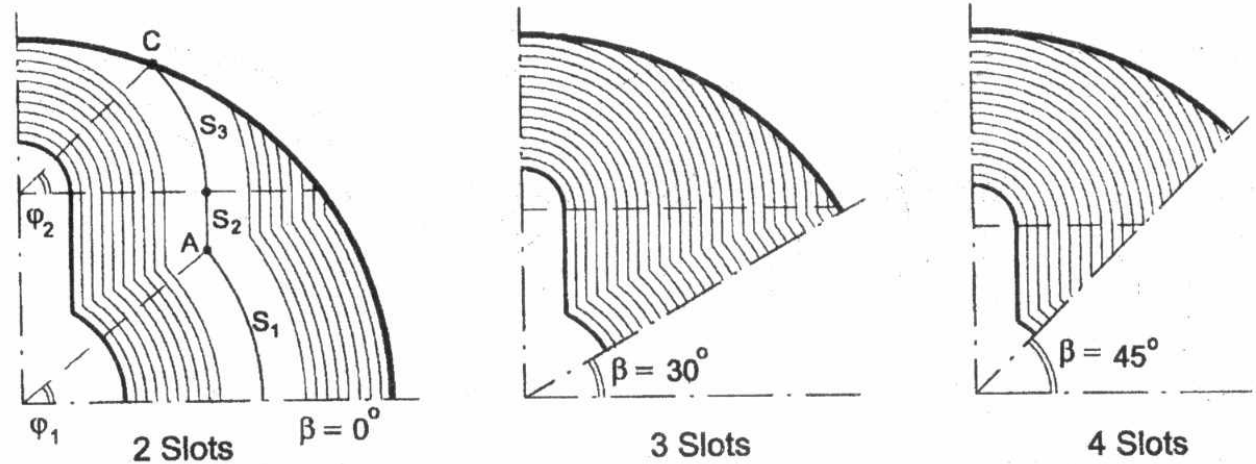

Fig. 14 The burning perimeters of short-slot grains
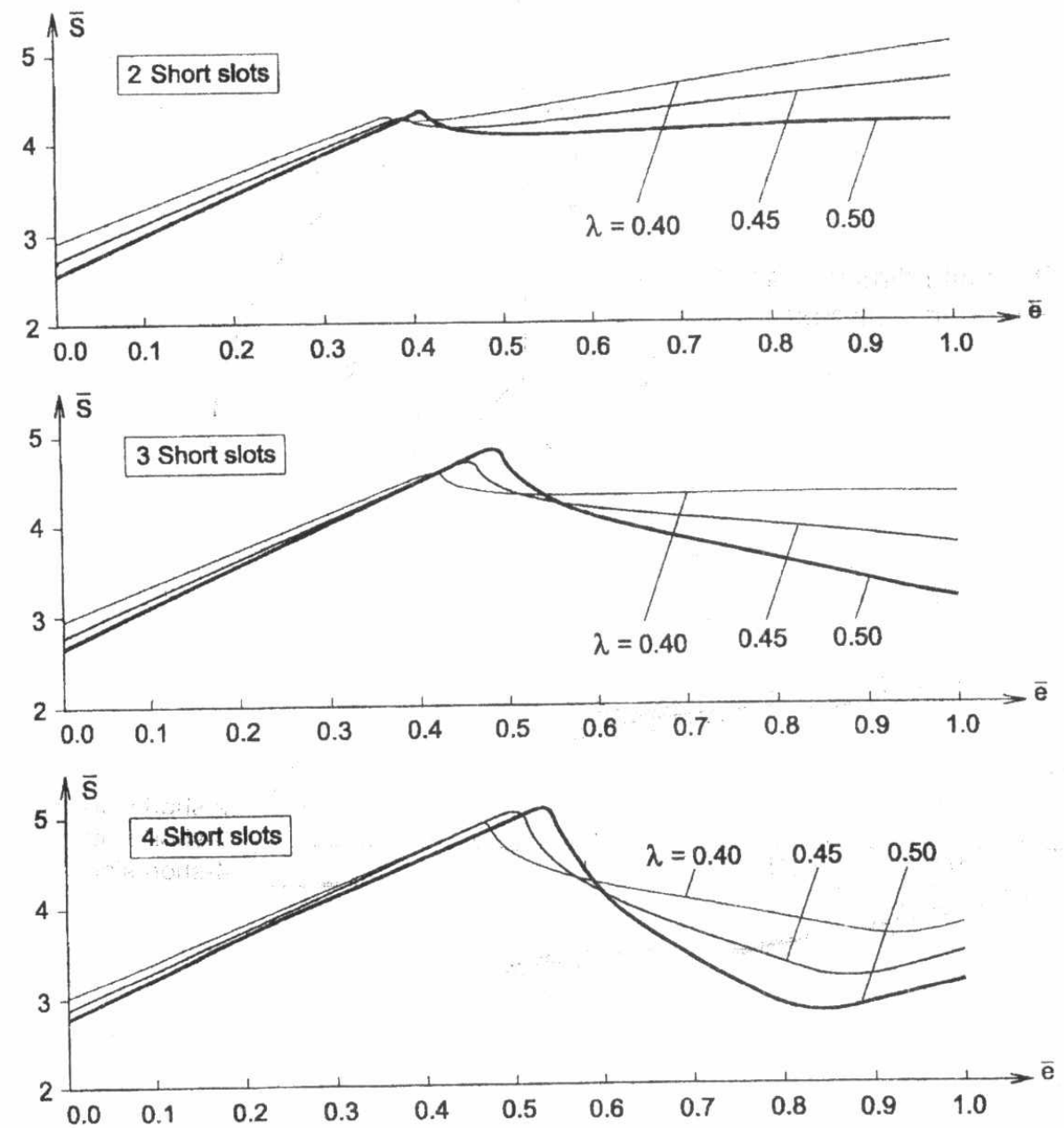

Fig. 15 The burning perimeters of short-slot grains 


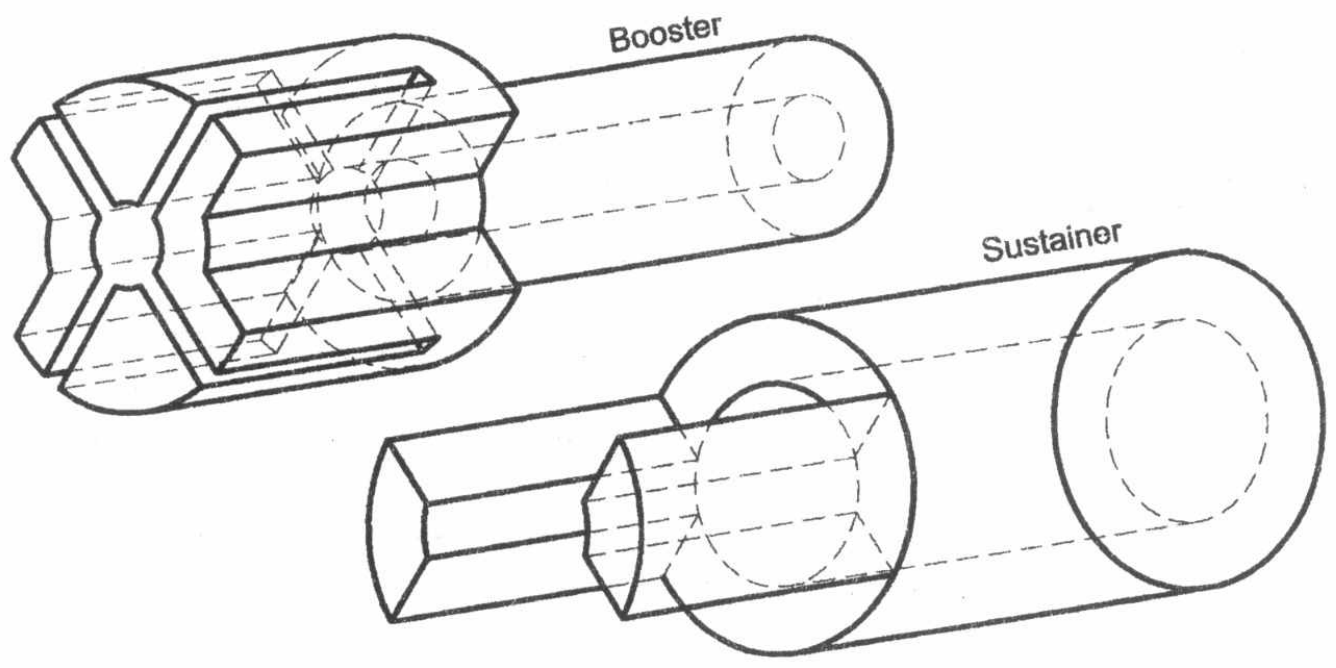

Fig. 16 3-D configuration of a slotted grain for dual thrust

Fig. 17 The Burning perimeters of the boosting and sustaining phases
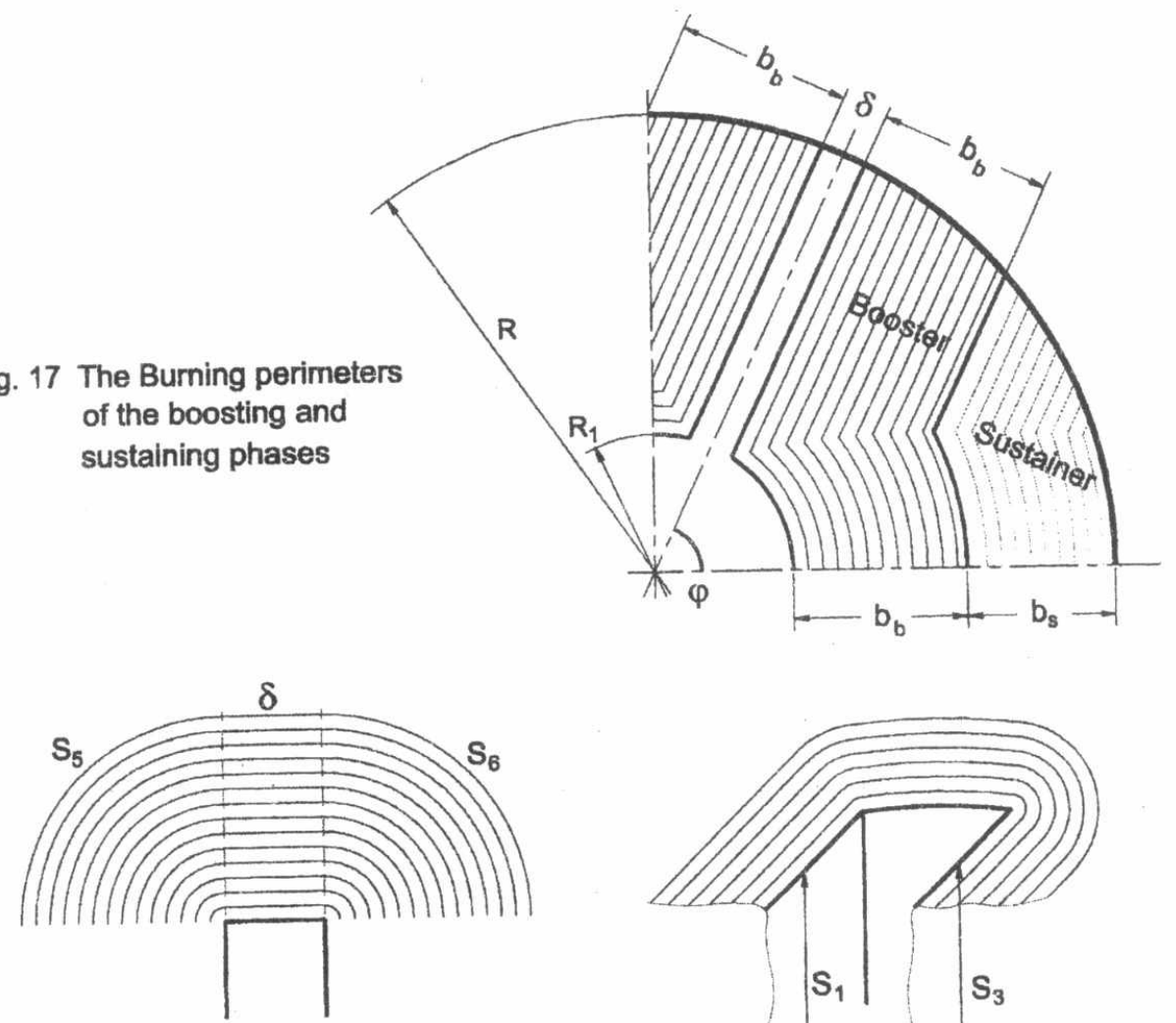

Fig. 18 The burning perimeter and surface

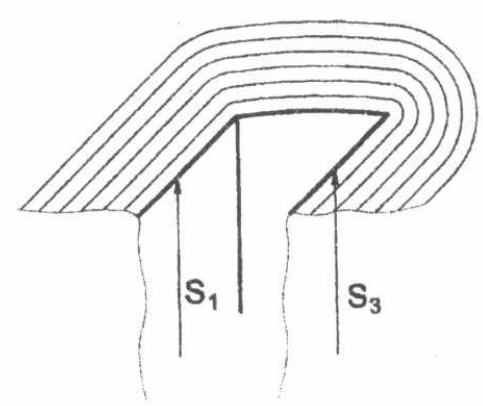
at ends of the slots 


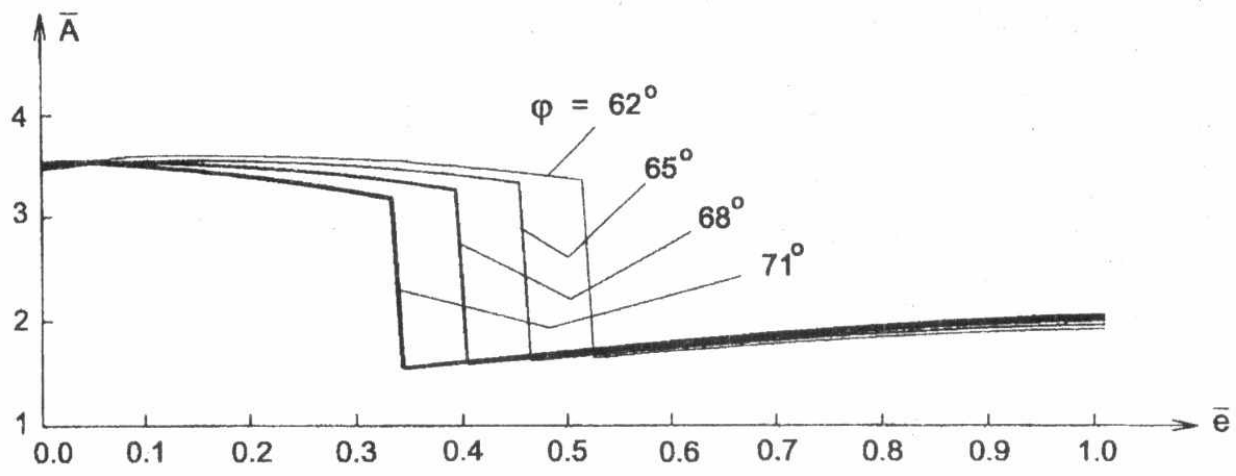

Fig. 19 The effect of the slot angle on the burning performance of dual thrust slotted grains at length ratio of 0.4

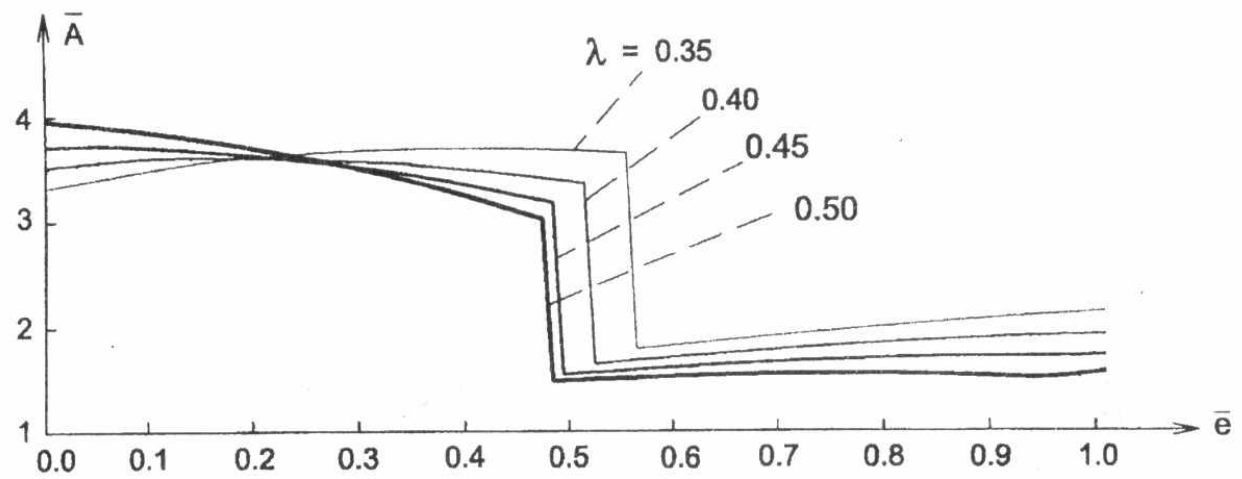

Fig. 20 The effect of the length ratio on the burning performance of dual thrust slotted grain with slot angle of $62^{\circ}$ 


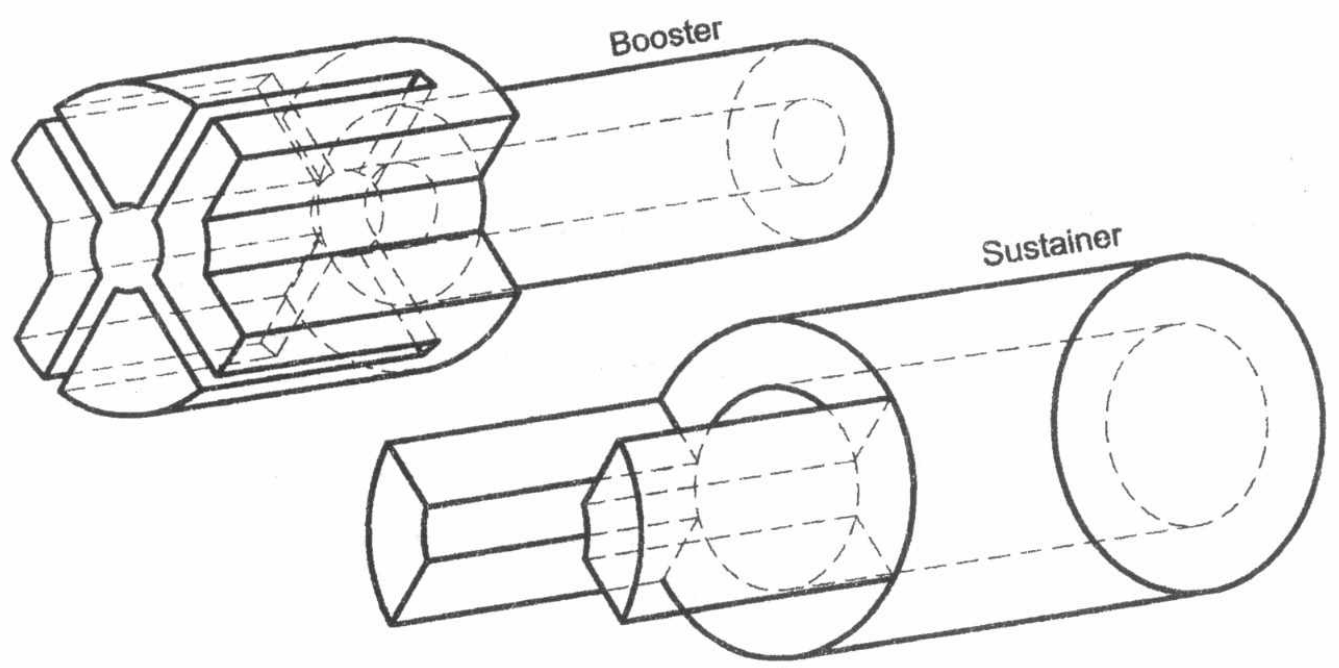

Fig. 16 3-D configuration of a slotted grain for dual thrust

Fig. 17 The Burning perimeters of the boosting and sustaining phases
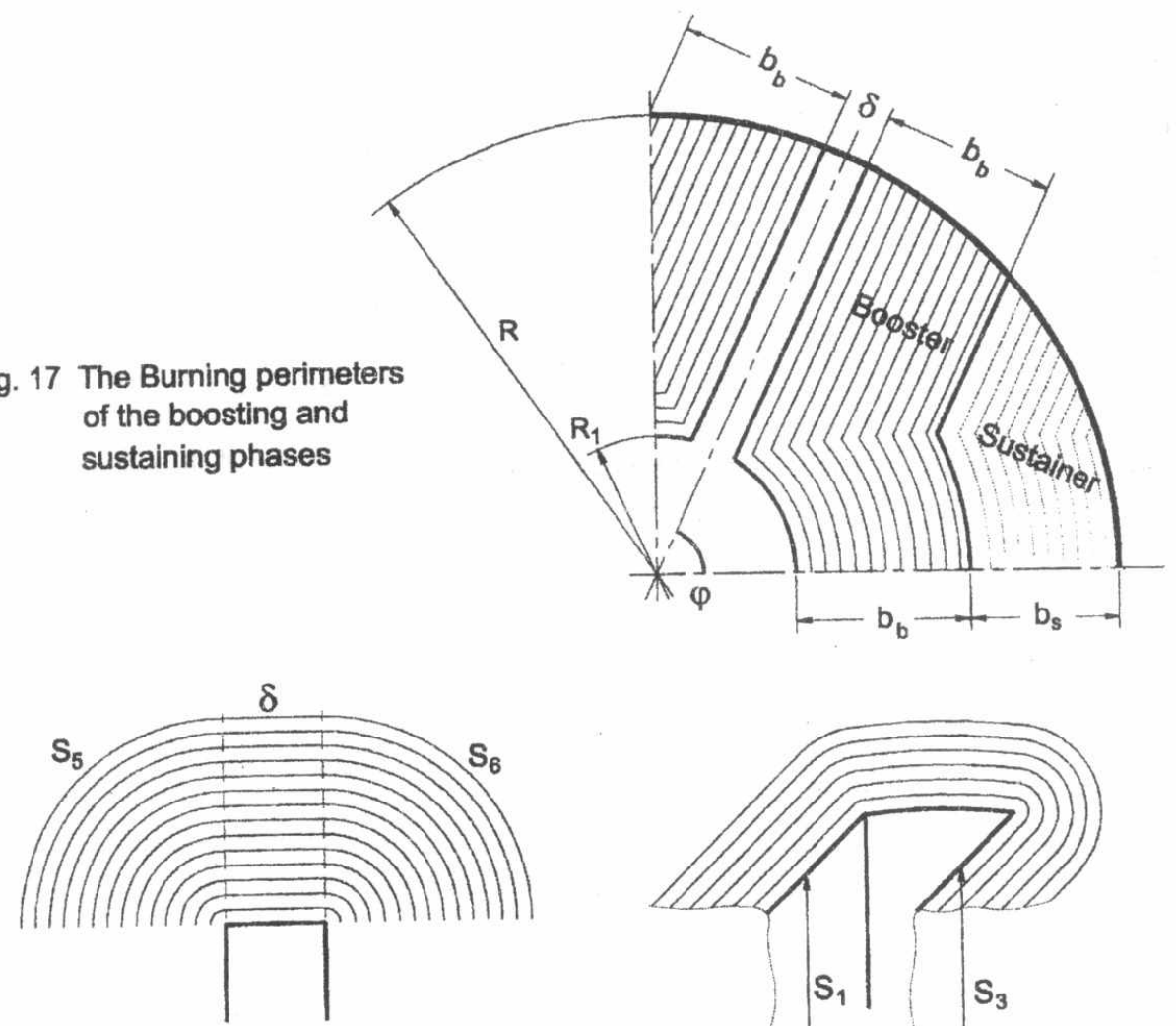

Fig. 18 The burning perimeter and surface

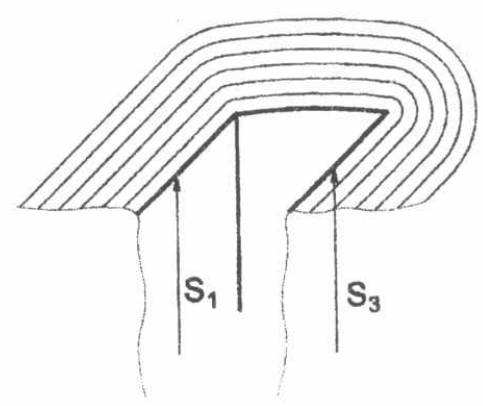
at ends of the slots 


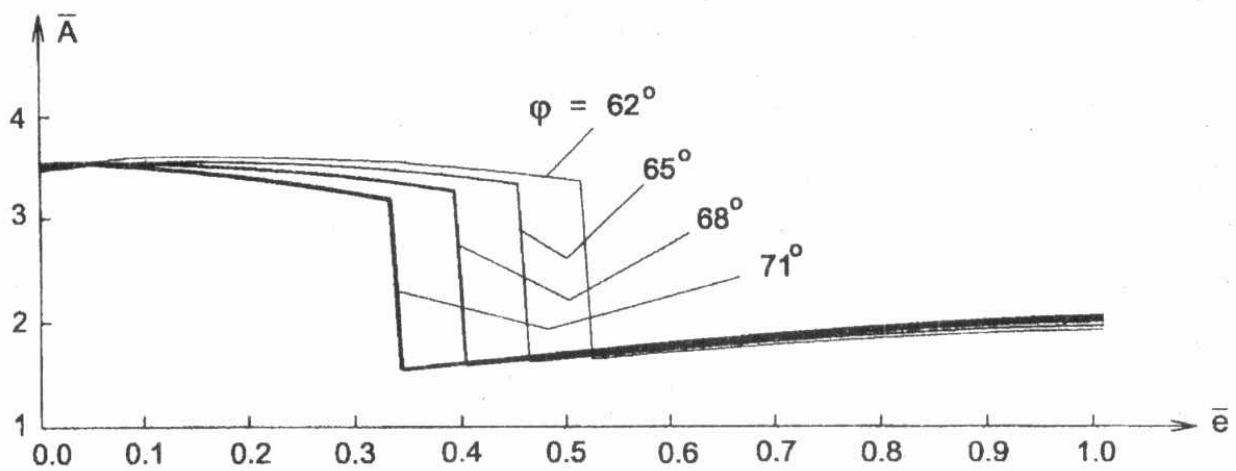

Fig. 19 The effect of the slot angle on the burning performance of dual thrust slotted grains at length ratio of 0.4

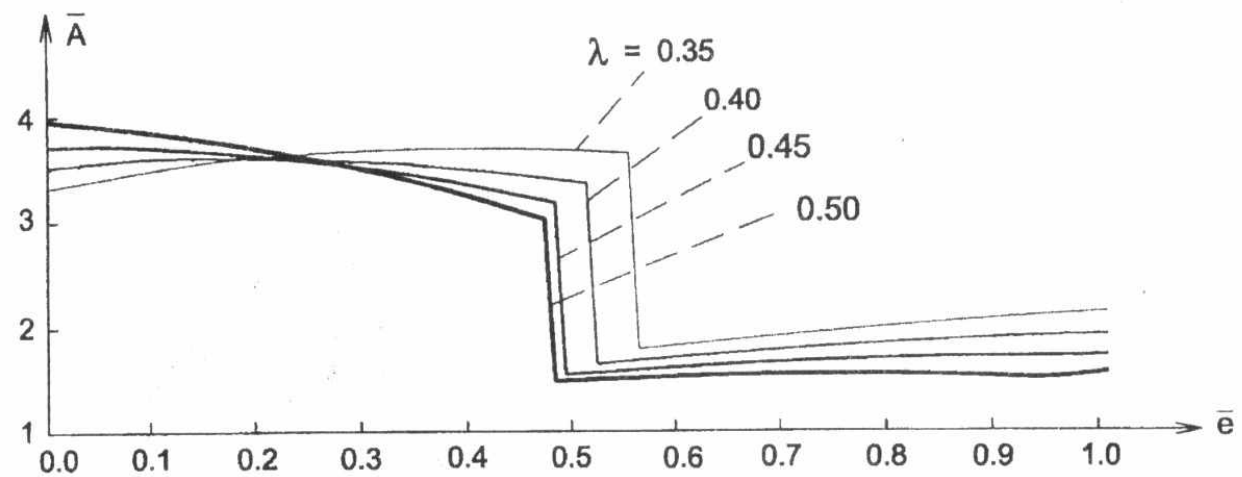

Fig. 20 The effect of the length ratio on the burning performance of dual thrust slotted grain with slot angle of $62^{\circ}$ 